\title{
Petri Nets Modelling and Analysis of the Veneer Layup System of Plywood Manufacturing Plant
}

\author{
Narendra Kumar(1), P.C. Tewari(2), Anish Sachdeva( ${ }^{(3)}$ \\ (1) Department of Mechanical Engineering, National Institute of Technology, Kurukshetra-136119, INDIA \\ e-mail: narendra_6160054@nitkkr.ac.in \\ (2) Department of Mechanical Engineering, National Institute of Technology, Kurukshetra-136119, INDIA \\ e-mail: pctewari1@rediffmail.com \\ (3) Department of Industrial and Prod. Engg., Dr. B.R. Ambedkar National Institute of Technology, Jalandhar-144011, INDIA \\ e-mail: asachdeva@nitj.ac.in
}

\section{SUMMARY}

In this paper performance behaviour is analysed in respect of the availability of the Veneer layup system of a plywood manufacturing plant. Generalized Stochastic Petri Nets (GSPN) technique is applied for modelling interactions among various components as well as the subsystems. The effects of the failure and repair rates, as well as availability of repair facilities on the behaviour of the system is investigated using a licensed software package. The outcomes will provide guidelines for the effective maintenance priorities to the practitioners and help in selecting appropriate maintenance strategies.

KEY WORDS: $\quad$ availability, modelling tools, maintenance, Petri Nets.

\section{INTRODUCTION}

With the increase in complexity due to the advancement in technology and fulfillment of required demands has made process industries highly competitive. Plywood industries come under the categories where the crisis of availability of wood and demands of quality, safety, and cost effectiveness make it very challenging. Other alternative decorative materials being used in place of the plywood is another major challenge to sustain it with compromising beatable prices. An additional stocking of spare parts burdens it with financial investment. Moreover, shortage might result in heavy penalties in terms of finance or other forms such as losing reputation, withdrawal of placed order, and fatal accidental failure, etc. Modern business leaders and practitioners have to take this challenge as an opportunity for survival and success. Reliability, Availability, and Maintainability (RAM) studies help in analyzing the maintenance issues and keeping appropriate maintenance stocks of spare parts. In 1997, Tan and Kramer [1] presented an estimate for the unplanned shutdown of a plant costs revenue loss of 500-100000 Dollars per hour. More recently, Gupta et al. [2] show the effect of 
variations in failure and repair rates of a generator of a power plant on its availability and profitability. In the present study, detailed investigations of the performance of a realistic industrial system of a plywood manufacturing plant is conducted. The system consisting of several dependent subsystems with a time-dependent failure model is considered. Generalized Stochastic Petri Nets (GSPN) approach is used to model and evaluate the system behavior in terms of its availability as well as its reduced capacity mode. The study is intended to demonstrate the use of RAM approaches in various stages of the plant life cycle of such systems. This is amply demonstrated in our present study. The next section describes certain modeling tools that can help in RAM practices.

\section{MODELING TOOLS}

Basically modeling tools are quantitative as well as qualitative methods and techniques that can be used for making a mathematical model of interactions among the various units/subsystems considering suitable predefined values and assumptions. These are now available commercially in the form of software packages and help in making decisions on RAM issues. Some of the popular modeling tools are (i) Fault Tree Analysis (ii) Reliability Block Diagram (iii) Markov and (iv) Petri Nets. Fault Tree modeling technique is a non-state space method of analysis. It was developed at Bell Telephone Laboratory in 1962. This technique uses a combination of logical relationships between events which lead to system failure and is called the top event. Reliability Block Diagram is also a non-state space modeling method. It represents graphically how the components of a system are connected reliability wise. In the reliability block diagram, each component of the system represents a block. Based on the operational dependency between the components, these are connected in series and /or parallel or hybrid configurations.

However, the above mentioned non-space state methods cannot handle complex situations such as failure/repair dependencies, shared maintenance facilities for different units that have different effects, and have different resource requirements. In such situations, more detailed state space methods such as the Markov chain model and Petri Nets are preferred.

Markov method is a powerful modeling and analysis tool. It has applications in analyzing time-based reliability and availability analysis. Okafor et al.[3], Gupta and Tewari [4], Kumar and Modgil [5], Tomasz et al. [6], Dahiya et al. [7] and recently Gupta et al.[2] have used Markov birth-death process technique to formulate the mathematical performance model of the system and evaluate its availability measures. However, a major limitation of this modeling tool is its state`s explosion even though it is applied to relatively small systems. Petri Nets modelling is comparatively simple. It also eliminates certain limitations of the Markov method. Petri Nets modelling and its subsequent extensions are briefly described as under.

Petri Nets (PN) is a graphical modeling tool proposed by C. A. Petri in his doctoral thesis in 1962. Since then, many extensions to this technique have been developed to further enhance its modeling power and application to analyze a wide range of industrial and non-industry related problems. It consists of places, transitions, arcs, and tokens. Tokens are kept in places and these move from one place to another along arcs through transitions. An illustrative PN model is shown in Figure 1. Marking is the assignment of tokens to the places and these may change during the execution of a Petri Net. Petri net is called Stochastic Petri Net (SPN) if the transition firing times are stochastically timed. Marsan et al. [8] described Generalized Stochastic Petri Nets (GSPN) as an extension of SPN that allows the transitions of the 
underlying PN to belong to two different classes, namely immediate and timed transitions. Immediate transitions are drawn as black bars that once enabled fire in zero time whereas timed transitions having assigned firing rates are denoted as unfilled rectangular boxes (shown in Figure 1). To reduce the limitations of GSPN Dugan et al.[9] at Duke university in 1984 proposed an extended class of SPN called Extended Stochastic Petri Net (ESPN). It includes inhibitor arcs, counter arcs, and probabilistic arcs. In this net, it is possible to use customized firing time distributions. It is best suited for the system with assembly lines. A further extension of GSPN is Deterministic Stochastic Petri Net (DSPN) which allows defining immediate, exponentially distributed, and deterministically timed transitions. The graphical representation of DSPN is the same as GSPN except for some specified firing conditions [25]. Colored Petri Net (CPN) is a high level PN proposed by Kurt Jensen [10]. It is based on the concept of colored tokens to distinguish various elements. Multicolor tokens identifying a particular type of subsystem use the same place and transitions to fire in the normal way, except for a specified condition. Petri net has been well surveyed by different researchers as well as in some textbooks from time to time [25]. The present study highlights the significance of PN in the field of RAM studies.

The paper is intended to demonstrate the superiority of the PN approach over the Markov modeling technique in many aspects. This technique considerably reduces the tedious computational efforts that are usually required as in the case of the Markov method. These allow a process designer to focus more on the system being modeled rather than on tedious and error prone manual construction of Markov chains. Simulations on Petri Nets are very flexible and provide accurate predictions for the system performance measures. The number of simulation runs required for computing availability measure results depends on the desired accuracy of output measures. Whereas in Markov approach generally one failure is considered at a time and failure pattern is normally taken to be exponential, PN based technique can handle more than one failure with different types of time-dependent failure models. This method is also being currently extensively applied in the area of dependability analysis. In fact, certain efficient pieces of software based on this technique such as the Petri module of GRIF are now also commercially available. Due to this, we preferred to use the PN technique in this study and the licensed software tool named Petri module of GRIF for computations. However, the results presented in earlier published Sachdeva et al. [11,12], Kumar et al. [22] and Malik and Tewari [24] validate and strengthen the significance of the present work.
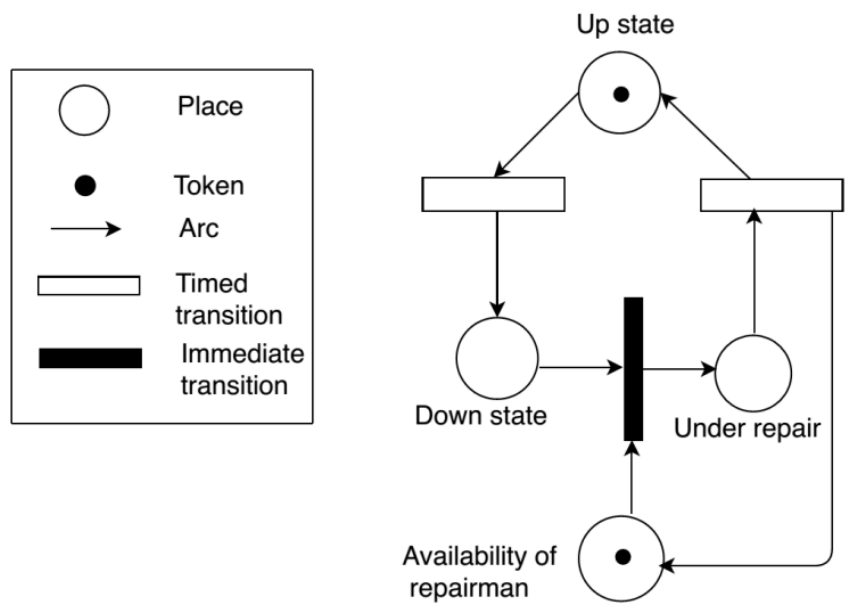

Fig. 1 An illustrative Petri nets model 


\section{LITERATURE REVIEW}

In the last decade, a number of authors have published research papers on the successful application of RAM approaches for the availability analysis of industrial systems. Narahari and Vishwanadham [13] used a PN based approach for modeling and analyzing the availability of flexible manufacturing systems (FMS). Sachdeva et al. [11,12] used the PN modeling technique for analyzing and evaluating the performance of various systems of a paper manufacturing plant. Kumar et al. [14] performed an availability analysis of the feeding system of a paper industry using the PN approach. Bernardin Peros performed a RAM analysis of the bearing capacity of structures considering dynamic actions of dominant wind load [15]. Dekker and Groenendijk [16] discussed typical applications of various RAM tools in certain industrial practices. Singh and Garg [17] performed an availability assessment of a plywood manufacturing plant using the Markov technique. Trivedi et al. [18] described several stochastic modeling techniques and their subsequent extensions for secure and survivable systems. Thangamani [19] applied the GSPN technique to carry out the availability analysis of a Lube oil system which is used in a combined cycle power plant. Haisheng Li et al. [20] carried out modeling and availability analysis of a navigation satellite using CPN formalism. Angel A. [21] proposed an analytical model that uses the SPN technique for developing an intelligent emergency evacuation system in buildings which may be used on accidental fire occurrence. More recently, Kumar et al. [22] used GSPN formalism to perform the availability analysis of the refrigeration system of a milk processing plant.

\section{SYSTEM DESCRIPTION}

In this study, a plywood manufacturing plant located in the Ganga basin of Northern India is considered. This plant consists of interconnected units such as debarking, block cutting, veneer making, steaming, drying, and layup as shown in Figure 2. One of its important functional units is Veneer layup which is considered as the system.

Some of the major functional units considered as subsystem are:

I. Glue Spreader: The purpose of glue spreader is to spread glue over the veneer surfaces uniformly. It consists of driving rollers, motor, and gluing rollers. Gluing rollers are provided to glue both sides simultaneously. Motors are being used to drive rolls as well as the conveyor. Failure generally occurs due to the failure of the motor and/or gluing rollers.

II. Heat press: It is used for properly hot pressing of the layers of veneer. It is provided with PLC controlled electric heating coils. The major part of this subsystem is the hydraulic unit that provides power for the press capacity of around 120 tons. A $42 \mathrm{~mm}$ thick plate is provided to ensure uniform pressing of the veneer. Failure usually occurs on account of the delivery pump of the hydraulic unit and electrical heating coils.

III. Trimming Saw: This subsystem is used for the final size edge cutting of plywood. For longitudinal cutting and cross cutting, it is provided with alloy saw blades. Saw blades have a rotation speed of around $6900 \mathrm{rpm}$. It can cut around 800 sheets of boards per hour. The working process is controlled by PLC. Failure generally occurs on account of the failure in PLC and saw blades. 


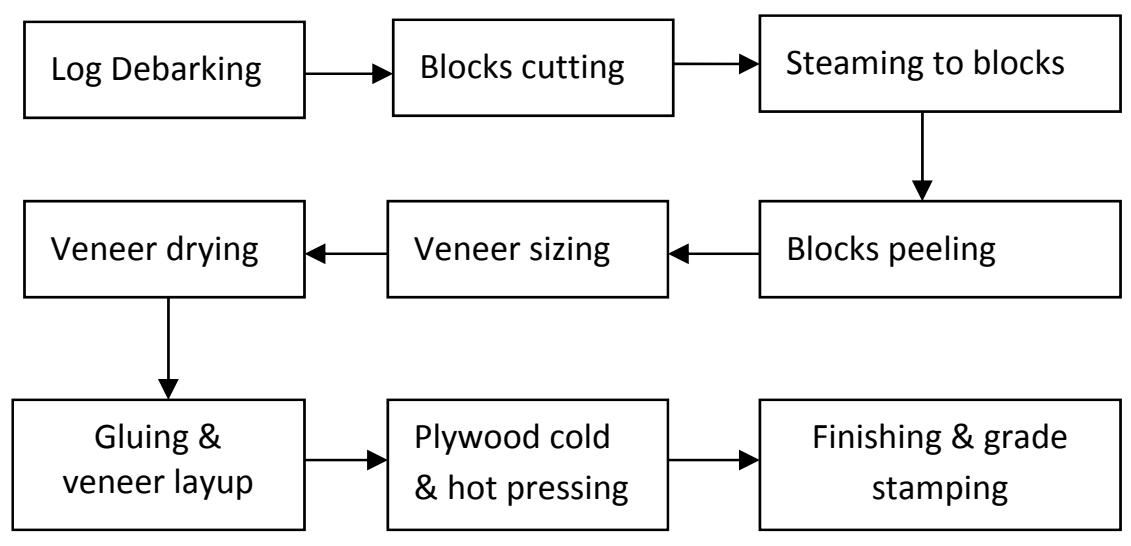

Fig. 2 Flow Diagram of Plywood Manufacturing

\section{PETRI NETS MODELLING OF THE SYSTEM}

This section describes the Petri Nets model of the Veneer lay-up system of leading a Plywood manufacturing Plant located in Haryana, India. Programming is done considering various parameters and their suitable predefined values. It is shown diagrammatically in Figure 3. Generalized Stochastic Petri Nets are used to show interactions among various subsystems. The available failure and repair data is presented in Table 1. Mean Time Between Failure (MTBF) and Mean Time to Repair (MTTR) were obtained from the maintenance logbook of the plant in consultation with the supervisors. In the present model, a single repair facility is available and as a result, all the failures cannot be handled together. Consequently, failed subsystems have to be put in a queue and these have to wait for the repair. Given this, a place is assigned to several repair facilities in the model to analyze the impact of the availability of repair facilities on the performance of the system. Moreover, the model has also been programmed to study concurrently the effect of system performance in reduced capacity mode.

Following assumptions and notations have been used to analyze the performance of the modeled system:

i) Failure follows the Weibull distribution pattern and repair follows an exponential distribution.

ii) Standby systems are as good as the active systems.

iii) System can work at reduced capacity mode.

iv) Failures do not occur simultaneously.

v) Repaired subsystem is as good as new.

vi) Repairs can be started without delay.

In the model, places are represented by a circle, whereas transitions are represented by a bar. These have the following meanings:

\section{Places:}

- sys_available represents the system in the upstate.

- sys.works_full cap. represents the system working in full capacity. 
- sys.works_red.cap. represents the system working in a reduced capacity.

- sys_failed represents the system in the downstate.

- repair.facility_available represents the availability of the repair facilities.

- spreader_up, press_up, and saw_up denote the working states of glue spreaders, heat press, and trimming saws respectively.

- spreader_dn, press_dn, and saw_dn represent the down states of glue spreaders, heat press and trimming saws respectively.

- spreader_rep, press_rep, and saw_rep represent the repair states glue spreaders, heat press, and trimming saws respectively.

Transitions:

- spreader_fail, press_fail, and saw_fail denote timed transitions and are associated with failure patterns of glue spreaders, heat press and trimming saws. These are denoted by $\mathrm{MTBF}_{1}, \mathrm{MTBF}_{2}$ and $\mathrm{MTBF}_{3}$ respectively.

- spreader_ok, press_ok, and saw_ok denote timed transitions and associated repair rates $\left(\mu_{1}, \mu_{2}\right.$ and $\left.\mu_{3}\right)$ of glue spreaders, heat press and trimming saws respectively.

- rep.avail_spreader, rep.avail_press, and rep.avail_saw denote immediate transitions and the associated availability of repair facilities for glue spreaders, heat press and trimming saws respectively.

- Sys_red, sys_recovered, sys_fail, and sys_ok denote immediate transitions which are fired without delay once. These are associated with the system when it works either with full capacity or reduced capacity.

\section{Programmed guard functions:}

The guard functions associated with different transitions are as described below:

- $[\mathrm{g} 1]=(\# 2>0$ and $\# 14>0)$ disables the transition rep.avail_spreader.

- $[\mathrm{g} 2]=(\# 5>0$ and $\# 14>0)$ disables the transition rep.avail_press.

- $[\mathrm{g} 3]=(\# 2>0$ and $\# 14>0)$ disables the transition rep.avail_saw.

- $[\mathrm{g} 4]=(\# 2>0$ or $\# 3>0)$ or $(\# 1>0$ and $\# 1<2)$ enables the transition sys_red.

- $[\mathrm{g} 5]=(\# 1>1$ and $\# 4>0$ and $\# 7>2)$ disables the transition sys_recovered.

- $[\mathrm{g} 6]=((\# 2>0$ and $\# 3>0)$ or $(\# 5>0$ or $\# 6>0)$ or $(\# 8>1$ and $\# 9>0))$ enables the transition sys_fail.

- $[\mathrm{g} 7]=(\# 1>0$ and $\# 4>0$ and $\# 7>0)$ disables the transition sys_ok.

Table 1 Failure and Repair data of Plywood Layup System

\begin{tabular}{|l|c|c|c|c|}
\hline \multirow{2}{*}{$\begin{array}{l}\text { Name of the } \\
\text { subsystem }\end{array}$} & \multicolumn{3}{|c|}{ Weibull parameters of Failure data } & $\begin{array}{c}\text { Exponentially } \\
\text { distributed repair data }\end{array}$ \\
\cline { 2 - 5 } & $\begin{array}{l}\text { Shape } \\
\text { parameter } \\
(\beta)\end{array}$ & $\begin{array}{l}\text { Scale } \begin{array}{l}\text { Sarameter } \\
(\theta)\end{array} \\
\text { Glue Spreaders }\end{array}$ & $\begin{array}{l}\text { Mean Time } \\
\text { Between Failure } \\
(\text { MTBF }) \text { hrs. }\end{array}$ & Repair rate $\left(\mu_{i}\right)$ per $h r$. \\
\hline Heat press & 1.10 & 655 & 310.0 & $8.0 \times 10^{-2}$ \\
\hline Trimming saws & 1.21 & 287 & 200.0 & $5.0 \times 10^{-2}$ \\
\hline
\end{tabular}




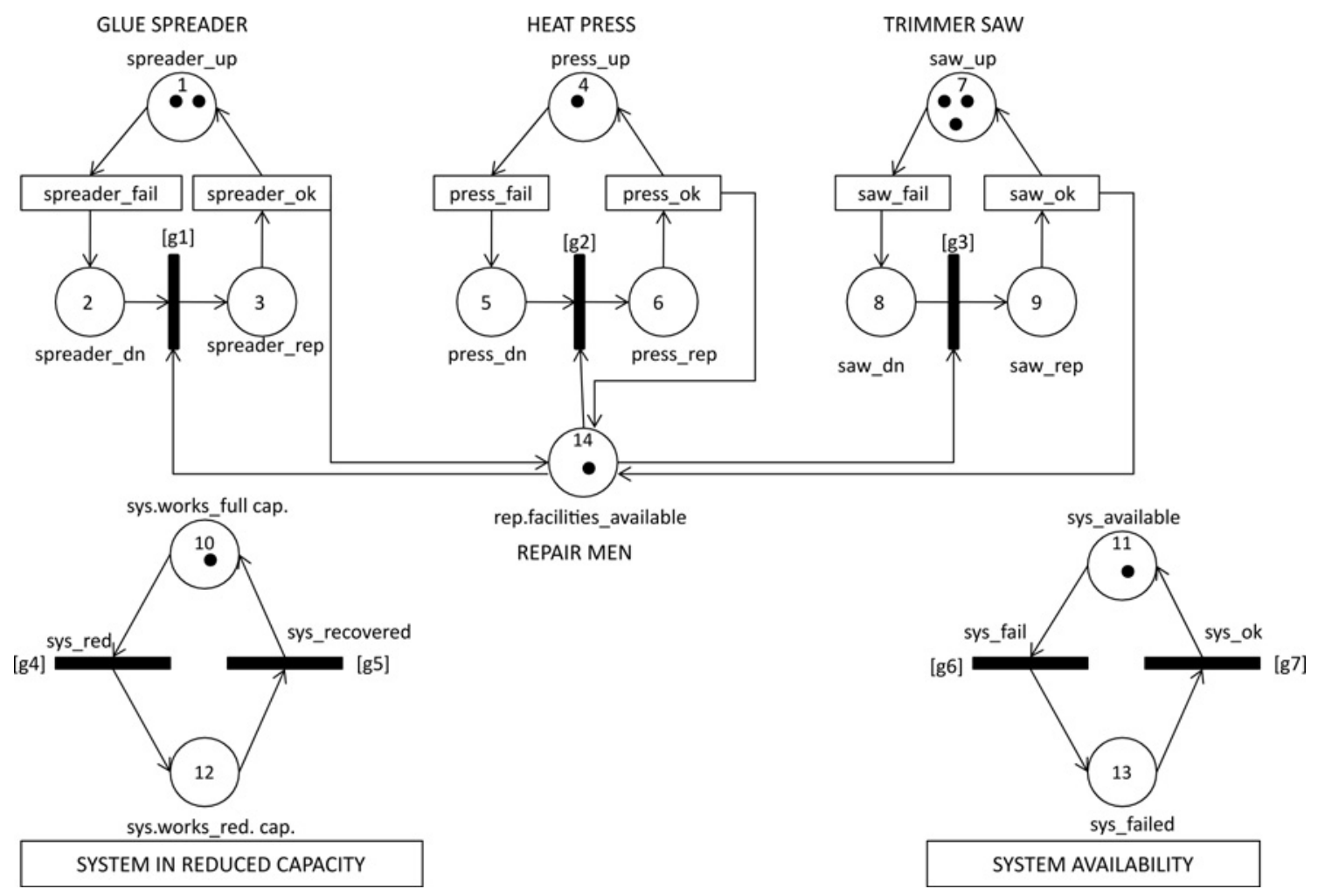

Fig. 3 The Petri Nets Model of the Veneer Layup System

\section{PERFORMANCE ANALYSIS}

Performance analysis is carried out to understand its long-run performance in terms of availability. Petri Nets technique is used for this purpose. The performance modeling was carried out using a licensed Petri Nets software package named GRIF-predicates Petri module using various parameters with their suitably predefined values. In this study, whereas the failure pattern was considered to follow Weibull distribution, repair rates were assumed to follow exponential distribution patterns. The plant behavioral characteristics were obtained using Monte Carlo simulation up to 10000 hours and around 21000 replications at a 95\% confidence level.

In order to analyze the performance, repair, and failure rates of each subsystem were varied within permissible ranges keeping the other subsystem parameters constant. The results are presented in Tables 2 to 8 . The maximum availability of the system is found to be $95.88 \%$ at a $95 \%$ confidence level. The impact on the performance of the system with variation in values of the parameters of considered subsystems is discussed thereafter.

Table 2 Effect of variations in the MTBF and repair rates of the glue spreader on system availability (\%)

\begin{tabular}{|c|c|c|c|c|c|c|}
\hline 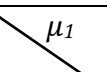 & 0.02 & 0.05 & 0.08 & 0.11 & 0.14 & Constant Parameters \\
\hline 390.0 & 0.9371 & 09540 & 09578 & 09584 & 09588 & \multirow{5}{*}{$\begin{array}{l}(M T B F)_{2}=200, \mu_{2}=0.05 \\
(M T B F)_{3}=350, \mu_{3}=0.11\end{array}$} \\
\hline 350.0 & 0.9363 & 0.9536 & 0.9563 & 0.9577 & 0.9580 & \\
\hline 310.0 & 0.9263 & 0.9530 & 0.9542 & 0.9552 & 0.9570 & \\
\hline 270.0 & 0.9230 & 0.9515 & 0.9529 & 0.9544 & 0.9559 & \\
\hline 230.0 & 0.9105 & 0.9498 & 0.9507 & 0.9535 & 0.9548 & \\
\hline
\end{tabular}


Table 3 Effect of variations in the MTBF and repair rates of the glue spreader on the reduced capacity (\% of the time)

\begin{tabular}{|c|c|c|c|c|c|c|}
\hline$\mu_{1}$ & 0.02 & 0.05 & 0.08 & 0.11 & 0.14 & Constant Parameters \\
\hline 390.0 & 14.21 & 6.54 & 4.58 & 3.69 & 3.19 & \multirow{5}{*}{$\begin{array}{l}(M T B F)_{2}=200, \mu_{2}=0.05 \\
(M T B F)_{3}=350, \mu_{3}=0.11\end{array}$} \\
\hline 350.0 & 15.73 & 7.13 & 4.95 & 3.97 & 3.40 & \\
\hline 310.0 & 17.68 & 7.93 & 5.47 & 4.34 & 3.70 & \\
\hline 270.0 & 20.04 & 8.95 & 6.11 & 4.82 & 4.08 & \\
\hline 230.0 & 23.20 & 10.31 & 6.97 & 5.45 & 4.58 & \\
\hline
\end{tabular}

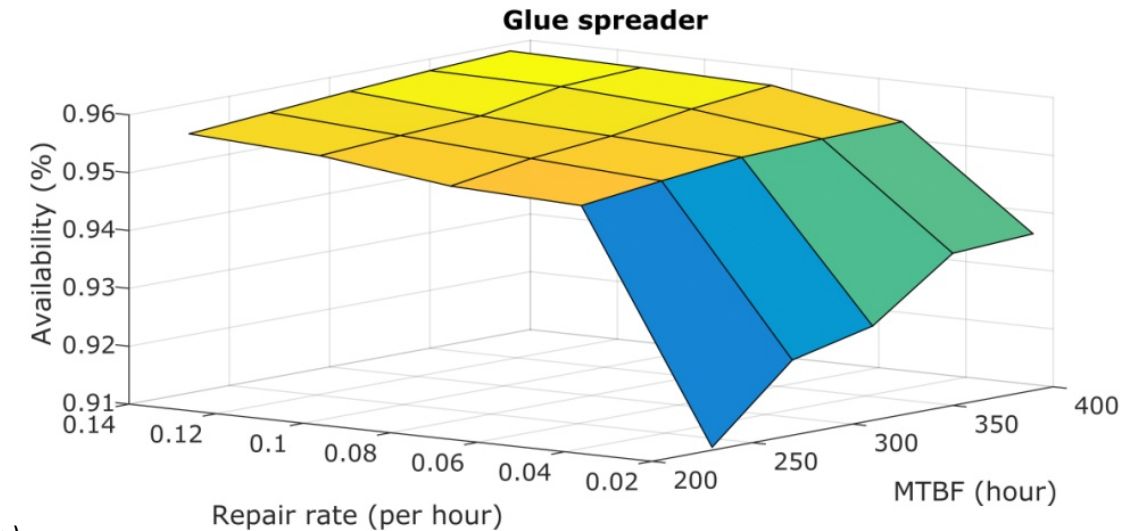

(a)

Repair rate (per hour)

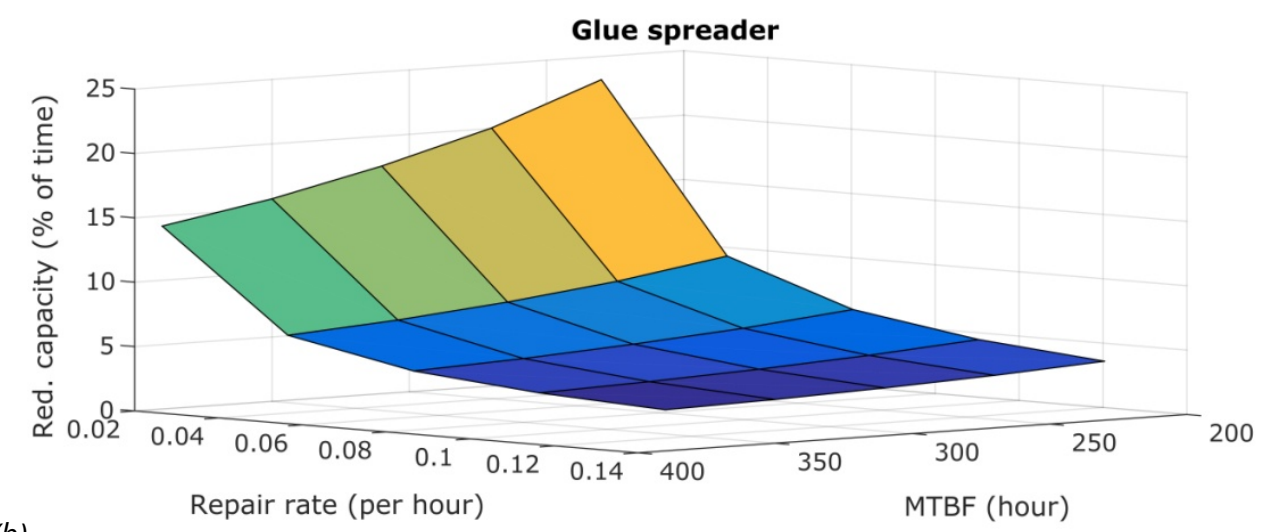

(b)

Fig. 4 Effect of failure and repair rates of glue spreader on (a) availability (b) reduced capacity

Figure 4 (a) shows that with variation in the failure and repair rates of the spreader, there is a moderate effect on the availability of the system. The decrease in the MTBF of the spreader from 390 to 230 and a reduction in the repair rates of this subsystem from 0.14 to 0.02 reduces the system's availability by not more than $4.83 \%$. However, identical variations in the failure and repair rates of glue spreader show a significant impact on the system's working in a reduced capacity of $20.01 \%$ of the time. This is shown in Figure 4 (b). 
Table 4 Effect of variations in the MTBF and repair rates of Heat Press on system availability (\%)

\begin{tabular}{|c|c|c|c|c|c|c|}
\hline & 0.01 & 0.03 & 0.05 & 0.07 & 0.09 & Constant Parameters \\
\hline 260.0 & 0.7210 & 0.8834 & 0.9258 & 0.9466 & 09588 & \multirow{5}{*}{$\begin{array}{l}(M T B F)_{1}=310, \mu_{1}=0.08 \\
(M T B F)_{3}=350, \mu_{3}=0.11\end{array}$} \\
\hline 230.0 & 0.6984 & 0.8718 & 0.9207 & 0.9409 & 0.9526 & \\
\hline 200.0 & 0.6647 & 0.8542 & 0.9049 & 0.9321 & 0.9459 & \\
\hline 170.0 & 0.6262 & 0.8304 & 0.8926 & 0.9187 & 0.9340 & \\
\hline 140.0 & 0.5846 & 0.8064 & 0.8773 & 0.9060 & 0.9223 & \\
\hline
\end{tabular}

Table 5 Effect of variations in the MTBF and repair rates of Heat press on reduced capacity (\% of the time)

\begin{tabular}{|c|c|c|c|c|c|c|}
\hline 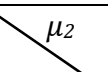 & 0.01 & 0.03 & 0.05 & 0.07 & 0.09 & Constant Parameters \\
\hline 260.0 & 12.78 & 4.75 & 3.69 & 3.34 & 3.19 & \multirow{5}{*}{$\begin{array}{l}(M T B F)_{1}=310, \mu_{1}=0.08 \\
(M T B F)_{3}=350, \mu_{3}=0.11\end{array}$} \\
\hline 230.0 & 13.83 & 4.98 & 3.78 & 3.39 & 3.22 & \\
\hline 200.0 & 14.98 & 5.26 & 3.92 & 3.47 & 3.27 & \\
\hline 170.0 & 16.23 & 5.63 & 4.10 & 3.58 & 3.34 & \\
\hline 140.0 & 17.95 & 6.12 & 4.33 & 3.73 & 3.44 & \\
\hline
\end{tabular}

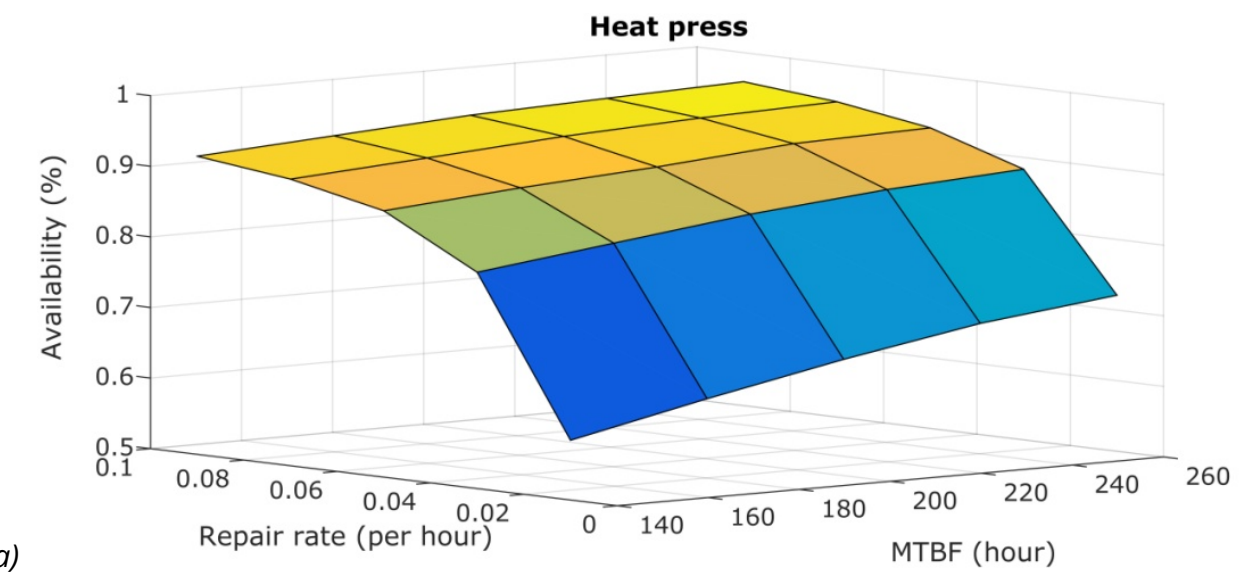

(a)

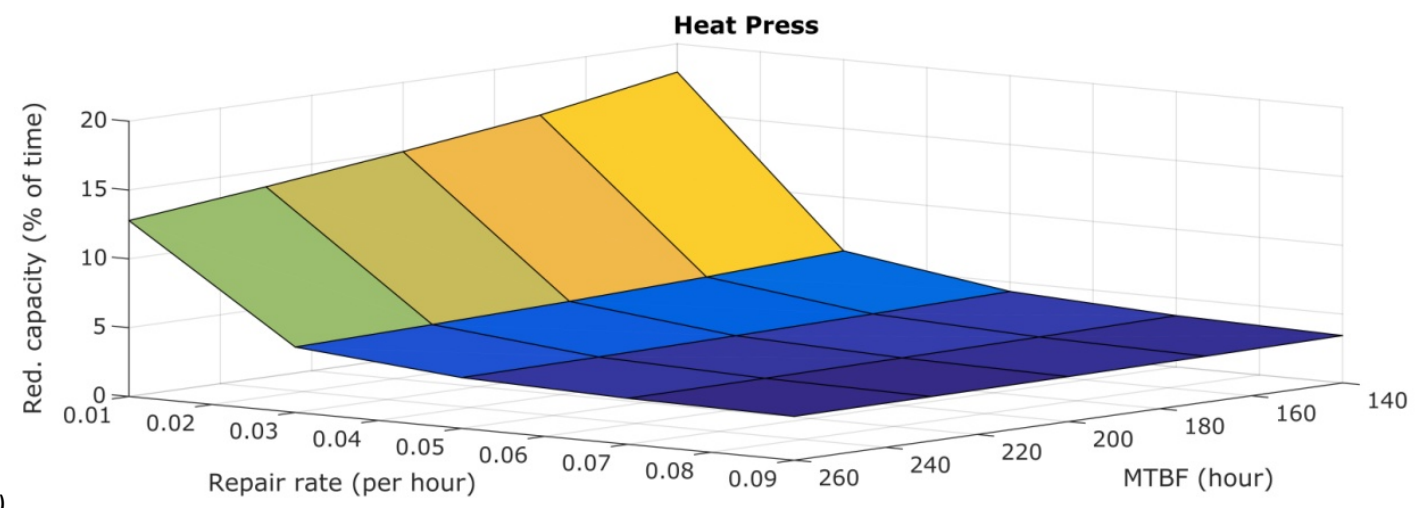

Fig. 5 Effect of failure and repair rates of the heat press on (a) availability (b) reduced capacity

Figure 5 (a) reveals that with variation in the failure and repair rates of the heat press there is a significant effect on the availability of the system. The decrease in the MTBF of the heat press from 260 to 140 and a reduction in repair rates of the same from 0.09 to 0.01 reduce the system's availability by as much as $37.42 \%$. Similar variations in the failure and repair rates of 
the heat press show also a significant effect on the system's working in reduced capacity of $14.76 \%$ of the time. This is shown in Figure 5 (b).

Table 6 Effect of variations in MTBF and repair rates of Trimming saw on system availability (\%)

\begin{tabular}{|c|c|c|c|c|c|c|}
\hline 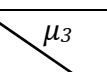 & 0.01 & 0.06 & 0.11 & 0.16 & 0.21 & Constant Parameters \\
\hline 450.0 & 0.8933 & 0.9381 & 0.9544 & 0.9566 & 0.9588 & \multirow{5}{*}{$\begin{array}{l}(M T B F)_{1}=310, \mu_{1}=0.08 \\
(M T B F)_{2}=200, \mu_{2}=0.05\end{array}$} \\
\hline 400.0 & 0.8880 & 0.9351 & 0.9539 & 0.9560 & 0.9577 & \\
\hline 350.0 & 0.8769 & 0.9322 & 0.9481 & 0.9555 & 0.9569 & \\
\hline 300.0 & 0.8616 & 0.9293 & 0.9477 & 0.9549 & 0.9560 & \\
\hline 250.0 & 0.8310 & 0.9260 & 0.9450 & 0.9535 & 0.9552 & \\
\hline
\end{tabular}

Table 7 Effect of variations in MTBF and repair rates of Trimming saw on reduced capacity (\% of time)

\begin{tabular}{|c|c|c|c|c|c|c|}
\hline & 0.01 & 0.06 & 0.11 & 0.16 & 0.21 & Constant Parameters \\
\hline 450.0 & 24.42 & 5.93 & 4.18 & 3.29 & 3.19 & \multirow{5}{*}{$\begin{array}{l}(M T B F)_{1}=310, \mu_{1}=0.08 \\
(M T B F)_{2}=200, \mu_{2}=0.05\end{array}$} \\
\hline 400.0 & 27.36 & 6.42 & 4.46 & 3.71 & 3.33 & \\
\hline 350.0 & 30.77 & 7.03 & 4.80 & 3.96 & 3.52 & \\
\hline 300.0 & 35.35 & 7.91 & 5.29 & 4.30 & 3.78 & \\
\hline 250.0 & 41.11 & 9.04 & 5.90 & 4.72 & 4.10 & \\
\hline
\end{tabular}

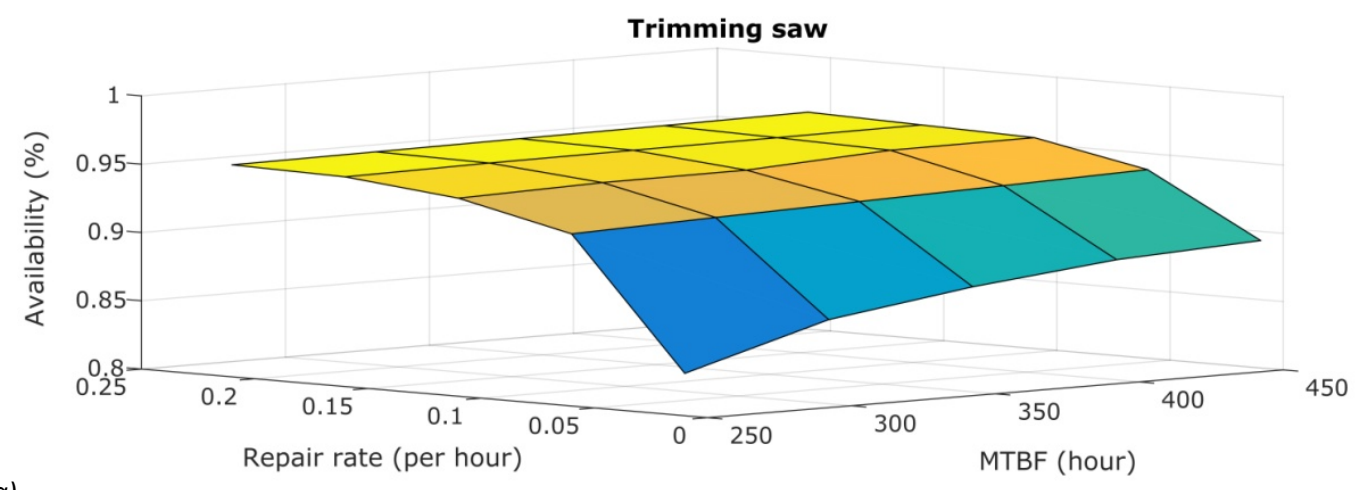

(a)

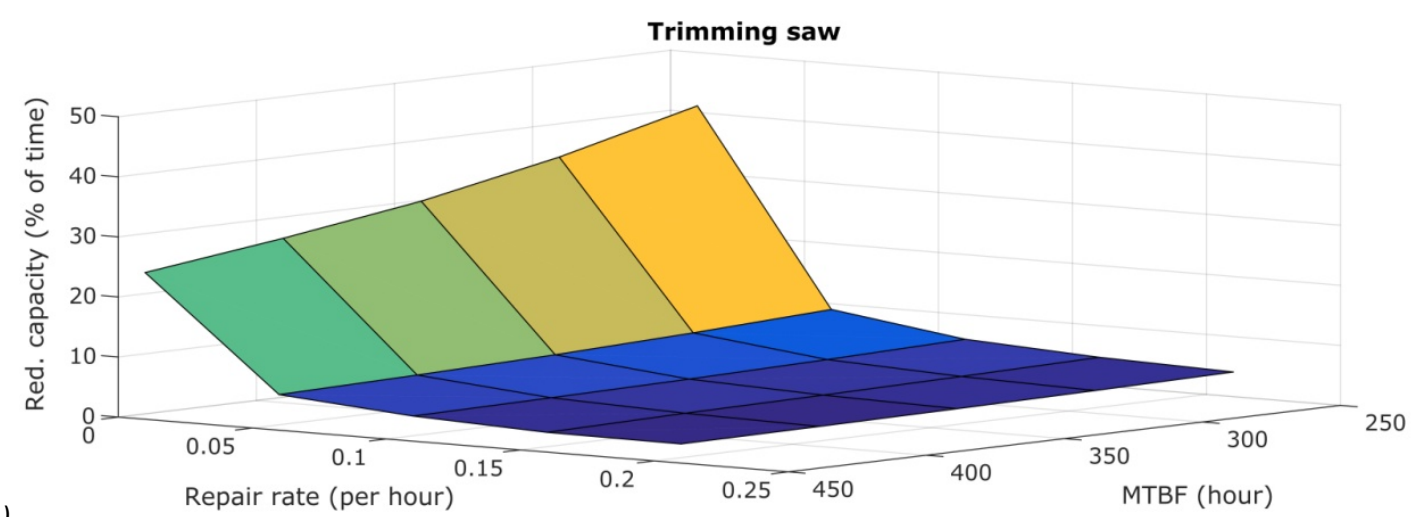

(b)

Fig. 6 Effect of failure and repair rates of the trimming saw on (a) availability (b) reduced capacity

Figure 6 (a) reveals that variation in the failure and repair rates of the trimming saw have a moderate effect on the availability of the system. The decrease in the MTBF of the spreader from 450 to 250 and a reduction in repair rate of the same from 0.21 to 0.01 reduces the 
system's availability by as much as $12.78 \%$. However, identical variations in failure and repair rates of the trimming saw show a greater impact on the system's working in reduced capacity of $37.92 \%$ of the time. This is shown in Figure 6 (b).

Table 8 Effect of repair facilities on the availability (\%) and reduced capacity (\% of the time) of the System

\begin{tabular}{|c|c|c|}
\hline No of Repair facilities & Availability (\%) & $\begin{array}{c}\text { System operational in reduced } \\
\text { capacity (\% of time) }\end{array}$ \\
\hline 1 & 0.9588 & 3.19 \\
\hline 2 & 0.9607 & 3.04 \\
\hline 3 & 0.9607 & 3.04 \\
\hline 4 & 0.9607 & 3.04 \\
\hline
\end{tabular}

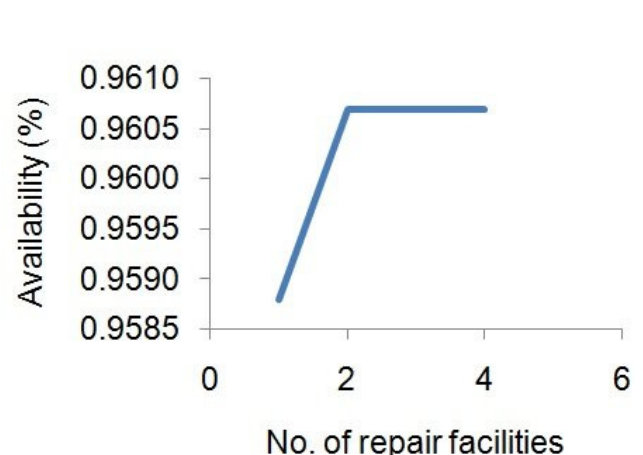

(a)

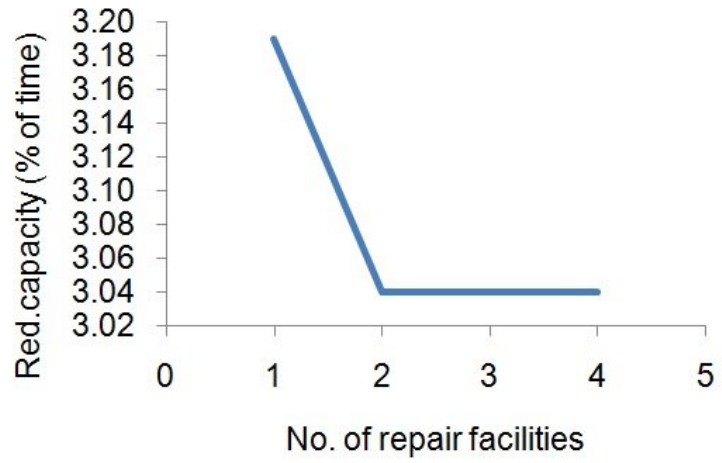

(b)

Fig. 7 Effect of failure and repair rates of the repair facilities on (a) availability (b) reduced capacity

Figure 7 clearly shows that with an increase in the repair facilities from one to four, the system's availability enhances as much as $0.19 \%$ and its availability in reduced capacity by $0.15 \%$ of the time.

\section{CONCLUSIONS}

Performance analysis carried out in the present study on different subsystems of the veneer layup system has shown that the heat press is the most critical subsystem which needs to be put on topmost priority in deciding its maintenance strategy which is not currently in practice. The failure of trimming saw takes the system into reduced capacity modes. Therefore, this subsystem also needs to be taken care of and given importance along with the heat press. The effect of repair facilities on the system's performance can further help in deciding the requirement of maintenance facilities allocations and reduce the unplanned breakdowns. The present study suggests that modification in the layup of Veneer is required. This will significantly reduce the amount of wastage in material and manpower. This study also highlights the usefulness of modeling tools. These can be used by practicing engineers concurrently in all phases of the plant life cycle of such systems. This will help in reducing the operation and maintenance costs and enhance the production volume as well. It will also help in improving the quality standards of the product.

Use of Petri Nets can help in reducing the tedious computational efforts required in the case of Markov and other similar modeling tools. In fact, the selection of an appropriate technique has a direct impact on operational and maintenance costs. It will be of interest to analyze the 
availability of such systems using non-traditional optimization techniques such as Teacher Learning Based Optimization (TLBO), Genetic Algorithm (GA), Particle Swarm Optimization (PSO), Ant Colony Algorithm, Immune Algorithm, Bumble Bees Mating Optimization algorithm and Biogeography Based Optimization (BBO) algorithm, etc. [5], [23] and [24]. These are robust and may give the best solution for complex systems.

\section{REFERENCES}

[1] J.S. Tan, M.A. Kramer, A general framework for preventive maintenance optimization in chemical process operations, Computers and Chemical Engineering, Vol. 21, pp. 14511469, 1997. https://doi.org/10.1016/S0098-1354(97)88493-1

[2] N. Gupta, M. Saini, A. Kumar, Operational availability analysis of generators in steam turbine power plants, SN applied sciences, Vol. 2 (779), 2020.

https://doi.org/10.1007/s42452-020-2520-y

[3] C.E. Okafor, A.A. Atikpakpa, U.C. Okonkwo, Availability assessment of steam and gas turbine units of a thermal power station using Markovian approach, Arch Curr Res Int, Vol. 6, No. 4, pp. 1-17, 2016. https://doi.org/10.9734/ACRI/2016/30240

[4] S. Gupta, P.C. Tewari, Simulation modeling and analysis of complex system of thermal power plant, J Ind Eng Manag, Vol. 2, No. 2, pp. 387-406, 2009.

https://doi.org/10.3926/jiem.2009.v2n2.p387-406

[5] A. Kumar, V. Modgil, Performance optimization for ethanol manufacturing system of distillery plant using particle swarm optimization algorithm, Int. J. Intelligent Enterprise, Vol. 5, No. 4, pp. 345-364, 2018. https://doi.org/10.1504/IJIE.2018.095723

[6] N. Tomasz, W.W. Sylwia, M. Chlebus, Reliability assessment of production processMarkov modelling approach, Intelligent systems in prod. Engg, Adv. In Intelligent Systems and Computing, 637, 2018.

[7] O. Dahiya, A. Kumar, M. Saini, Mathematical modeling and performance evaluation of apan crystallization system in a sugar industry, SN Appl Sciences, 2019.

https://doi.org/10.1007/s42452-019-0348-0

[8] M.A. Marsan, G. Conte, G. Balbo, A Class of Generalized Stochastic Petri Nets for the Performance Evaluation of Multiprocessor Systems, ACM trans. on Computer Systems, Vol. 2, No. 2, pp. 93-122, 1984. https://doi.org/10.1145/190.191

[9] J. Dugan, K. Trivedi, R. Geist, V. Nicola, Extended Stochastic Petri Nets: Application and Analysis, Proceedings of the Performance '84, Paris, France, pp. 507-519, 1984.

https://doi.org/10.21236/ADA148439

[10] K. Jensen, Colored Petri Nets and the invariant method, theoretical computer science, Vol. 14, pp. 317-336, 1981. https://doi.org/10.1016/0304-3975(81)90049-9

[11] A. Sachdeva, D. Kumar, P. Kumar, Reliability analysis of the pulping system using Petri Nets, International Journal of Quality \& Reliability Management, Vol. 25, No. 8, pp. 860877, 2008. https://doi.org/10.1108/02656710810898667

[12] A. Sachdeva, P. Kumar, D. Kumar, Behavioral and performance analysis of feeding system using stochastic reward nets, Int J Adv. Manuf. Technol, Vol. 45, pp. 156-169, 2009.

https://doi.org/10.1007/s00170-009-1960-8

[13] Y. Narahari, N. Vishwanadham, A Petri net approach to the modelling and analysis of flexible manufacturing systems, Annal of Operations Research, Vol. 3, pp. 449-472, 1985. 
https://doi.org/10.1007/BF02023780

[14] D. Kumar, I.P. Singh, J. Singh, Reliability analysis of the feeding system in the paper industry, Microelectron Reliab., Vol. 28, pp. 213-215, 1988.

https://doi.org/10.1016/0026-2714(88)90353-8

[15] B. Peros, Reliability analysis of the structures with a dominant wind load, International Journal for Engineering Modelling, Vol. 5, No. 3-4, 1992.

[16] R. Dekker, W. Groenendijk, Availability assessment methods and their application in Practice, Microelectron Reliab., Vol. 35, No. 9-10, pp. 1257-1274, 1995.

https://doi.org/10.1016/0026-2714(95)99376-T

[17] J. Singh, S. Garg, Availability Analysis of Core Veneer Manufacturing system in Plywood Industry, International Conference on Reliability and Safety Engineering, Indian Institute of Technology, Kharagpur, India, pp. 497-508, 2005.

[18] K.S. Trivedi, V. Jindal, S. Dharmaraja, Stochastic Modelling Techniques for Secure and Survivable Systems, In The Morgan Kaufmann Series in Networking, Information Assurance, Morgan Kaufmann, ISBN 9780123735669, pp. 171-207, 2008.

https://doi.org/10.1016/B978-012373566-9.50009-4

[19] G. Thangamani, Generalized Stochastic Petri Nets for Reliability Analysis of Lube Oil System with Common-Cause Failures, American Journal of Computational \& Applied Mathematics, Vol. 2, No. 4, pp. 152-158, 2012.

https://doi.org/10.5923/j.ajcam.20120204.03

[20] H. Li, H. Zheng, H. Zhao, Z. Zheng, Research on the Availability Analysis Method of Navigation Satellite Based on Petri Nets, China Satellite Navigation Conference (CSNC) 2018 Proceedings, pp. 127-136, 2018. https://doi.org/10.1007/978-981-13-0029-5 12

[21] A.S. Angel, R. Jayaparvathy, Performance modelling of an intelligent emergency evacuation system in buildings on accidental fire occurrence, Safety Science, Vol. 12, pp. 196-205, 2019. https://doi.org/10.1016/j.ssci.2018.10.027

[22] N. Kumar, P.C. Tewari, A. Sachdeva, Performance Modelling and Analysis of Refrigeration System of a Milk Processing Plant using Petri Nets, International Journal of Performability Engineering, Vol. 15, No. 7, pp. 1751-1759, 2019.

https://doi.org/10.23940/ijpe.19.07.p1.17511759

[23] A.M. Dalavi, P.J. Pawar, T.P. Singh, Determination of optimal tool path in drilling operation using Modified Shuffled Frog Leaping Algorithm, International Journal for Engineering Modelling, Vol. 32, No. 2-4, pp. 33-44, 2019.

https://doi.org/10.31534/engmod.2019.2-4.ri.01v

[24] S. Malik, P.C. Tewari, Performance modelling and maintenance priorities decision for water flow system of a coal based thermal power plant, Int. Journal of Quality and Reliability Management, Vol. 35, No. 4, pp. 1-16, 2018.

https://doi.org/10.1108/IJQRM-03-2017-0037

[25] N. Viswanadham, Y. Narahari, Performance modelling of automated manufact. systems, PHI learning pvt. Ltd, 2015. 